Results On analysis $85 \%$ of women had the dating scan between 11-14 weeks and the chorionicity was determined in 100\%.Only $67 \%$ had documented evidence of counselling for Down's syndrome screening out of which $29 \%$ had it done. Interestingly there were no fetal anomalies identified at the detailed scan at 20 weeks.

$85 \%$ of dichorionic twins and $90 \%$ of monochorionic twins delivered after 34 weeks of gestation. The overall survival rate from diagnosis to delivery for dichorionic twins was $97 \%$ and $95 \%$ for monochorionic twins. The caesarean section rate was $57 \%$ and the incidence of caesarean section for twin 2 was $4 \%$.

Abstract PP.74 Table
\begin{tabular}{lllll}
\hline Total & Normal & IUD & NN Deaths & NN Adms \\
\hline (MC) & $65 \%$ & $0 \%$ & $5 \%$ & $30 \%$ \\
(DC) & $77 \%$ & $1.5 \%$ & $1.5 \%$ & $20 \%$ \\
\hline
\end{tabular}

Conclusion The results emphasised the need for good documentation of antenatal counselling especially for down's syndrome screening. The interesting points of note were that the incidence of IUGR in dichorionic twins was $41 \%$ and in monochorionic twins was $25 \%$ and also the survival rate was similar irrespective of chorionicity. Prematurity was the commonest complication and the reason for neonatal admissions as well.

\section{PP.75 EFFECT OF DRUG MISUSE ON MATERNAL AND NEONATAL OUTCOMES}

doi:10.1136/archdischild-2013-303966.352

\section{Vaughan, F Mackie, K Appiah-Sakyi. Pennine Acute Care Trust, Oldham, UK}

Drug and alcohol misuse during pregnancy is often associated with adverse fetal and maternal outcomes, due to the direct effect of the substances on woman and fetus and the generally chaotic lifestyles commonly observed among individuals that abuse drugs. We undertook an audit of mothers who abused alcohol and drugs in Pennine Acute NHS Trust, focusing on the outcomes during the antenatal period, labour, and the postnatal period, as well as the engagement of the mother with antenatal services.

Converse to our expectations, the outcomes for substance-abusing women in the Trust were not overly poor. $71 \%$ of pregnancies encountered no fetal problems, with $21 \%$ suspected IUGR and $8 \%$ other problems, including polyhydramnios, oligohydramnios and reduced fetal movement. $81 \%$ of women experienced no problems during delivery; maternal pyrexia $(4 \%)$, uterine rupture $(0.6 \%)$, preeclampsia $(0.6 \%)$ and hypertension $(0.6 \%)$ were among the difficulties encountered. All 155 women had live-births, with 11 neonates requiring admission to the Special Care Baby Unit. $90 \%$ of the babies were discharged home with the mother, with $8 \%$ going into foster care and the remainder going to another family member's home.

We believe that these positive outcomes could be related to the engagement with antenatal services noted, as the average number of antenatal contacts was 9 visits. This suggests that a dedicated drug and alcohol misuse team are vital in ensuring that substance misusers are engaging with antenatal services, and receiving the care necessary to maximise the chances of a normal pregnancy and the delivery of a healthy baby.

\section{PP.76 USE OF ULTRASOUND IN MANAGEMENT OF OBESITY IN PREGNANCY - CURRENT PRACTISE IN THE WEST OF SCOTLAND}

doi:10.1136/archdischild-2013-303966.353

${ }^{1} \mathrm{P}$ Wu, ${ }^{2} \mathrm{M}$ McMillan, ${ }^{1 H}$ Moss, ${ }^{1} \mathrm{JL}$ Gibson. ${ }^{1}$ Southern General Hospital, Glasgow, UK; ${ }^{2}$ Princess Royal Maternity Hospital, Glasgow, UK
For a 3-month period, a prospective audit of management of obesity in pregnancy was undertaken in Glasgow and Clyde maternity hospitals.

Two hundred and fourteen women were identified out of a total of 3,834 deliveries during the study period: $76(36 \%)$ had a booking body mass index (BMI) $\geq 40$ and 138 (64\%) had a BMI of 35-39.

One hundred and ninety-nine women (93\%) underwent fetal structural scan to screen for anomalies. Out of these, 168 (84\%) had it performed at recommended time period of $18-20+6$ weeks' gestation. Twenty-five (13\%) women had their structural scan between 21-24 weeks. One hundred and forty-one women (66\%) had a complete structural scan at first visit, and the remainder were offered repeat scan. Fifty-five (28\%) women returned for rescan and 44 $(22 \%)$ women had a complete structural survey then.

The assessment of fetal growth was performed in 170 (79\%) women, with $43(20 \%), 42(20 \%)$ and $59(28 \%)$ of women having had 1, 2 or 3 growth scans. Twenty-six (12\%) women had more than 3 scans. At the first growth scan, only $17(10 \%)$ women had a macrosomic fetus with an abdominal circumference $(A C)>95^{\text {th }}$ centile, while $5(3 \%)$ had a fetal $\mathrm{AC}<5^{\text {th }}$ centile. One hundred and three (48\%) women were delivered by Caesarean sections, and 47 of these were performed as emergency surgeries.

In conclusion, there is scope for improvement in sonographic surveillance of these high risk pregnancies. The effective use of sonographic resources may be best achieved by a planned ultrasound schedule.

\section{PP.77 WITHDRAWN BY AUTHOR}

\section{PP.78 WITHDRAWN BY AUTHOR}

\section{PP.79 CHARACTERISTICS AND OUTCOMES OF TEENAGE MOTHERS IN CAMBRIDGE}

doi:10.1136/archdischild-2013-303966.354

T Johal, S Bhatti. Addenbrookes Hospital, Cambridge, UK

Background Teenage pregnancy is traditionally associated with significant medical problems including pre-eclampsia, pre-term delivery, low birth weight and increased perinatal morbidity and mortality.

Rationale The aim of this audit was to study the obstetric and neonatal outcomes of our local pregnant teenage population and adherence to our guidelines.

Methods Data from 68 teenagers (under 19 years) who delivered in Cambridge between June 2010 and May 2011 was studied retrospectively.

Results $69 \%$ of the teenagers booked for antenatal care prior to 12 weeks. $46 \%$ were employed or in full time education. $50 \%$ of the teenagers smoked during pregnancy and rates of alcohol consumption $(8 \%)$ and substance misuse (3\%) were low. Antenatal care attendance was good; only $1.4 \%$ missed two or more antenatal appointments.

Obstetric complication rates were in keeping with the general population. These included gestational diabetes $(2.9 \%)$, preeclampsia (4.4\%), intrauterine growth restriction $(1.4 \%)$ and obstetric cholestasis $(1.4 \%)$. The Caesarean section rate was only $7.3 \%$ while $19 \%$ women had instrumental deliveries. $2.9 \%$ neonates had a birth weight under $2500 \mathrm{~g}$, and $4.4 \%$ required admission to special care. Breastfeeding initiation rates were low (35\%) and only $11 \%$ had post-natal contraception in place at the time of discharge by the community midwife.

Conclusions Contrary to previous research, our teenage population had similar obstetric and neonatal outcomes compared with the general population. As our population is relatively affluent, this may suggest that social circumstances have a larger role to play in adverse outcome than young maternal age alone. 